\title{
Article \\ SEC23B Loss-of-Function Suppresses Hepcidin Expression by Impairing Glycosylation Pathway in Human Hepatic Cells
}

\author{
Barbara Eleni Rosato ${ }^{1,2}$, Roberta Marra ${ }^{1,2}$, Vanessa D'Onofrio ${ }^{1,2}$, Federica Del Giudice ${ }^{2}$, Simone Della Monica ${ }^{1,2}$, \\ Achille Iolascon 1,2 (D) Immacolata Andolfo $1,2, *,+$ and Roberta Russo $1,2, *,+$ (D) \\ 1 Dipartimento di Medicina Molecolare e Biotecnologie Mediche, Università degli Studi di Napoli Federico II, \\ 80131 Napoli, Italy; rosato@ceinge.unina.it (B.E.R.); robertamarra.r@gmail.com (R.M.); \\ vanessa.donofrio2@gmail.com (V.D.); simonedellamonica28@gmail.com (S.D.M.); \\ achille.iolascon@unina.it (A.I.) \\ 2 CEINGE Biotecnologie Avanzate, 80145 Napoli, Italy; delgiudicef@ceinge.unina.it \\ * Correspondence: immacolata.andolfo@unina.it (I.A.); roberta.russo@unina.it (R.R.) \\ $\dagger$ These authors equally contributed.
}

check for updates

Citation: Rosato, B.E.; Marra, R.; D'Onofrio, V.; Del Giudice, F.; Della Monica, S.; Iolascon, A.; Andolfo, I. Russo, R. SEC23B Loss-of-Function Suppresses Hepcidin Expression by Impairing Glycosylation Pathway in Human Hepatic Cells. Int. J. Mol. Sci. 2022, 23, 1304. https://doi.org/ 10.3390/ijms23031304

Academic Editor: Paolo Arosio

Received: 29 December 2021

Accepted: 21 January 2022

Published: 24 January 2022

Publisher's Note: MDPI stays neutral with regard to jurisdictional claims in published maps and institutional affiliations.

Copyright: (C) 2022 by the authors. Licensee MDPI, Basel, Switzerland. This article is an open access article distributed under the terms and conditions of the Creative Commons Attribution (CC BY) license (https:// creativecommons.org/licenses/by/ $4.0 /)$

\begin{abstract}
Biallelic pathogenic variants in the $S E C 23 B$ gene cause congenital dyserythropoietic anemia type II (CDA II), a rare hereditary disorder hallmarked by ineffective erythropoiesis, hemolysis, erythroblast morphological abnormalities, and hypo-glycosylation of some red blood cell membrane proteins. Abnormalities in SEC23B, which encodes the homonymous cytoplasmic COPII (coat protein complex II) component, disturb the endoplasmic reticulum to Golgi trafficking and affect different glycosylation pathways. The most harmful complication of CDA II is the severe iron overload. Within our case series (28 CDA II patients), approximately $36 \%$ of them exhibit severe iron overload despite mild degree of anemia and slightly increased levels of ERFE (the only erythroid regulator of hepcidin suppression). Thus, we hypothesized a direct role of SEC23B loss-of-function in the pathomechanism of hepatic iron overload. We established a hepatic cell line, HuH7, stably silenced for $S E C 23 B$. In silenced cells, we observed significant alterations of the iron status, due to both the alteration in BMP/SMADs pathway effectors and a reduced capability to sense BMP6 stimulus. We demonstrated that the loss-of-function of SEC23B is responsible of the impairment in glycosylation of the membrane proteins involved in the activation of the BMP/SMADs pathway with subsequent hepcidin suppression. Most of these data were confirmed in another hepatic cell line, HepG2, stably silenced for SEC23B. Our findings suggested that the pathogenic mechanism of iron overload in CDA II is associated to both ineffective erythropoiesis and to a specific involvement of $S E C 23 B$ pathogenic variants at hepatic level. Finally, we demonstrated the ability of $S E C 23 B$ paralog, i.e., $S E C 23 A$, to rescue the hepcidin suppression, highlighting the functional overlap between the two SEC23 paralogs in human hepatic cells.
\end{abstract}

Keywords: congenital dyserythropoietic anemias; iron metabolism; SEC23B; glycosylation; hepcidin

\section{Introduction}

Congenital dyserythropoietic anemias (CDAs) are a group of rare hereditary disorders belonging to a subtype of bone marrow failure syndromes, characterized by monolineage involvement and morphological abnormalities in erythroid precursor cells [1]. CDAs are defined by maturation arrest of the erythroid lineage with the consequent reduced production of erythrocytes [1,2]. Among them, congenital dyserythropoietic anemia type II (CDA II) is the most common form. CDA II is an autosomal recessive disease characterized by iron-loading-anemia with relative reticulocytopenia (ineffective erythropoiesis) [3]. It is also characterized by the presence of bi- and multinucleated erythroblasts in bone marrow, with nuclei of equal size and DNA content [4]. Analysis of red cell membrane proteins by sodium dodecyl sulfate polyacrylamide gel electrophoresis (SDS-PAGE) identifies glycosylation abnormalities with fast moving band 3 (anion exchanger 1) and band 4.5 
(glucose transporter 1) [5,6]. This is due to the main biochemical feature of this hereditary disease: defective glycosylation [7]. Structural data of erythrocyte $\mathrm{N}$-glycans indicate that CDA II is not a distinct glycosylation disorder but is caused by a defect disturbing Golgi processing in erythroblasts [8]. CDA II results from homozygous or compound heterozygous loss-of-function mutations in SEC23B [9-11], one of the two paralogous SEC23 genes (SEC23A and SEC23B) that encodes a core component of COPII (coat protein complex II) vesicles [7]. COPII is a multi-subunit complex that mediates accumulation of secretory cargo, deformation of the membrane, and generation of subsequent anterograde transport of correctly folded cargo that bud from the ER towards the Golgi apparatus [12]. This pathway is critical for membrane homeostasis, localization of proteins within cells, and secretion of extracellular factors. Therapeutic strategies for CDA II only include supportive therapies, such as transfusion, splenectomy, and hematopoietic stem-cell transplantation in transfusion-dependent patients $[1,13,14]$.

The worst complication for patients with CDA II is the iron overload [15]. It has been reported that ineffective erythropoiesis results in strong down-regulation of the hepatic hormone hepcidin, increased iron absorption, and systemic iron overload, which is mediated by the erythroid hormone erythroferrone (ERFE) [16-19]. ERFE expression in CDA II patients is increased and related to abnormal erythropoiesis and acts by inhibiting hepatic signaling of BMP/SMADs [20,21]. The activation of the BMP/SMADs signaling requires, at hepatic level, the assembly of a multi-protein complex that senses and regulates the intracellular pathway that induces hepcidin transcription [22,23]. Although overexpression of ERFE was well documented in CDA II patients, no clear correlation between ERFE levels and iron balance has been proven so far [18,24]. This may suggest that ERFE cannot be the only regulator of hepcidin suppression in these patients.

We herein described a subset of CDA II patients showing iron overload even in presence of a mild degree of anemia and slightly increased levels of ERFE. Thus, we hypothesized a specific role of SEC23B loss-of-function in impairing iron metabolism at hepatic level. We demonstrate that the loss-of-function of SEC23B impairs the glycosylation of membrane proteins involved in the activation of the BMP/SMADs signaling with subsequent hepcidin suppression in $\mathrm{HuH7}$ cell line, a human hepatic model, stably silenced for SEC23B gene. Most of these data were confirmed in another hepatic cell line, HepG2, stably silenced for $S E C 23 B$.

\section{Results}

\subsection{Analysis of Iron Balance in Patients with CDA II}

Within our cohort of patients with CDA II enrolled in our Registry of hereditary anemias $[15,25,26]$, we selected 28 cases showing iron overload, defined as transferrin saturation (TSAT) $>45 \%$. We further stratified these patients into two subgroups according to the degree of anemia: (i) mild $(\mathrm{Hb} \geq 10.0 \mathrm{~g} / \mathrm{dL})$ and (ii) moderate/severe $(\mathrm{Hb}<10.0 \mathrm{~g} / \mathrm{dL})$ (Table 1). As expected, overall patients exhibited reduced hepcidin levels and high ferritin levels compared to reference ranges (Table 1). Moreover, all patients showed augmented EPO levels compared to reference range with a statistically significant increase in moderate/severe anemic subjects compared to the mild anemic ones. Nevertheless, we did not observe any difference in the ERFE levels between the two subgroups (Table 1). To further investigate on ERFE levels, we performed a correlation analysis on the entire case series between ERFE and EPO levels. Our data showed a slight, non-statistically significant, correlation between EPO and ERFE levels (Figure 1A). Similarly, we observed a negative correlation between hepcidin plasma levels and ERFE ones although the analysis did not reach the statistical significance (Figure 1B). 
Table 1. CDA II patients enrolled in the study.

\begin{tabular}{|c|c|c|c|c|c|}
\hline \multirow[t]{2}{*}{ Analysis } & \multirow[t]{2}{*}{ Units } & \multicolumn{2}{|c|}{ Chronic Anemia } & \multirow[t]{2}{*}{$p$-Value ${ }^{\dagger}$} & \multirow{2}{*}{$\begin{array}{c}\text { Reference } \\
\text { Range }\end{array}$} \\
\hline & & $\begin{array}{c}\text { Mild } \\
\mathrm{Hb} \geq 10.0 \mathrm{~g} / \mathrm{dL}\end{array}$ & $\begin{array}{c}\text { Moderate/Severe } \\
\mathrm{Hb}<10.0 \mathrm{~g} / \mathrm{dL}\end{array}$ & & \\
\hline $\mathrm{N}$ & & 10 & 18 & - & - \\
\hline Gender & male/female & $3(0.3) / 7(0.7)$ & $10(0.6) / 8(0.4)$ & 0.19 & - \\
\hline Age at sampling & years & $28.6 \pm 4.3$ & $17.0 \pm 5.7$ & 0.19 & - \\
\hline Hemoglobin & $\mathrm{g} / \mathrm{dL}$ & $10.9 \pm 0.2$ & $8.6 \pm 0.3$ & 0.00001 & $11.5-15.5$ \\
\hline ARC & $\times 10^{3} / \mu \mathrm{L}$ & $51.5 \pm 6.0$ & $77.7 \pm 14.7$ & 0.21 & 20-90 \\
\hline TSAT & $\%$ & $90.5 \pm 6.5$ & $76.7 \pm 4.6$ & 0.09 & $15-39$ \\
\hline hERFE & $\mathrm{ng} / \mathrm{mL}$ & $40.5 \pm 11.9$ & $43.2 \pm 9.3$ & 0.86 & $0.1-3.8$ \\
\hline $\mathrm{EPO}$ & $\mathrm{mIU} / \mathrm{mL}$ & $51.6 \pm 11.1$ & $151.1 \pm 27.4$ & 0.01 & $3.1-14.9$ \\
\hline sTfR & $\mathrm{mg} / \mathrm{L}$ & $3.8 \pm 0.5$ & $4.2 \pm 0.5$ & 0.59 & $0.78-1.89$ \\
\hline Hepcidin & $\mathrm{nM}$ & $5.6 \pm 2.3$ & $6.2 \pm 1.9$ & 0.85 & $\begin{array}{c}\text { male: } 40.10 \\
\text { female: } 23.27\end{array}$ \\
\hline Hepcidin/ferritin & - & $0.02 \pm 0.01$ & $0.03 \pm 0.01$ & 0.46 & - \\
\hline Ferritin & $\mathrm{ng} / \mathrm{mL}$ & $559.7 \pm 234.4$ & $369.2 \pm 115.2$ & 0.42 & $22.0-275.0$ \\
\hline Ferritin/age $§$ & - & $20.5 \pm 6.9$ & $57.9 \pm 19.9$ & 0.21 & - \\
\hline
\end{tabular}

ARC, absolute reticulocyte count; TSAT, transferrin saturation; sTfR, soluble transferrin saturation; EPO, erythropoietin; hERFE, human erythroferrone. Quantitative variables data are presented as mean \pm SEM. Qualitative variables data are presented as $\mathrm{n}(\%) / \mathrm{n}(\%) ;{ }^{\dagger}$ Student's $t$-test for quantitative unpaired data; chi-square tests for categorical data. $\S^{\S}$ Normalization of ferritin using "Ferritin level/dosage age ratio," as described by [27]

A

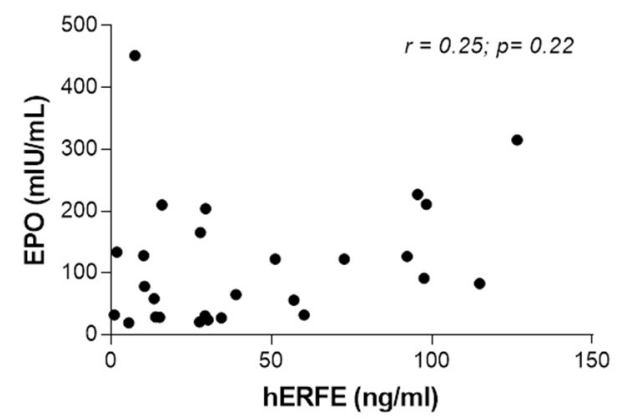

B

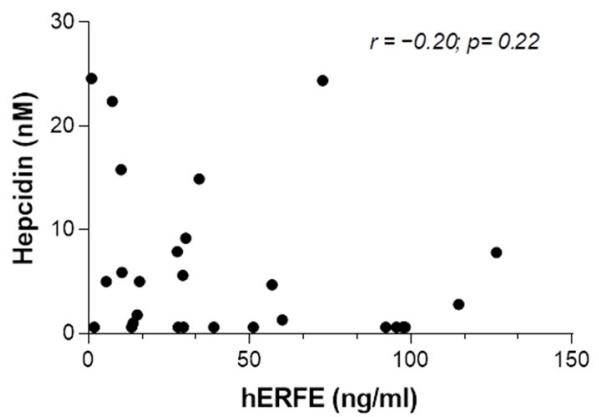

Figure 1. Correlation analysis between ERFE, EPO, and hepcidin levels. The graphs show the correlation analysis between ERFE and EPO levels (A) and between hepcidin and ERFE levels (B) in plasma samples from 28 CDA II enrolled in the study ( $\mathrm{r}$ and $p$-value by Pearson correlation analysis).

\subsection{Assessment of Iron-Related Genes in HuH7 Cells Stably Silenced for SEC23B}

ERFE levels were inadequate to explain hepcidin suppression in CDA II patients, so we investigated a possible specific role of SEC23B in hepcidin regulation. To reproduce $S E C 23 B$ loss-of-function at hepatic level, HuH7 cell lines stably silenced for SEC23B were generated by the means of small hairpin RNA (shRNA) method. The silencing efficiency was tested by qRT-PCR and Western blot analyses on both SEC23B and its paralogue SEC23A (Figure 2A,B). We observed downregulation of SEC23B expression in both sh$S E C 23 B-74$ and sh-SEC23B-70 clones compared to sh-CTR clone. Of note, the two silenced clones for $S E C 23 B$ showed different behaviors in terms of expression of $S E C 23 A$. Indeed, there was significant downregulation of SEC23A in the HuH7 sh-SEC23B-70 cells, which suggested a less-specific effect of the silencing in the HuH7 sh-SEC23B-70 cells (Figure 2A,B), whereas we observed a marked up-regulation of SEC23A in the HuH7 sh-SEC23B-74 cells compared to Sh-CTR ones, as expected for a CDA II model. Indeed, as observed in some CDA II patients, low $S E C 23 B$ expression alleles result in a compensatory increase in the paralog gene, SEC23A [28]. 
A
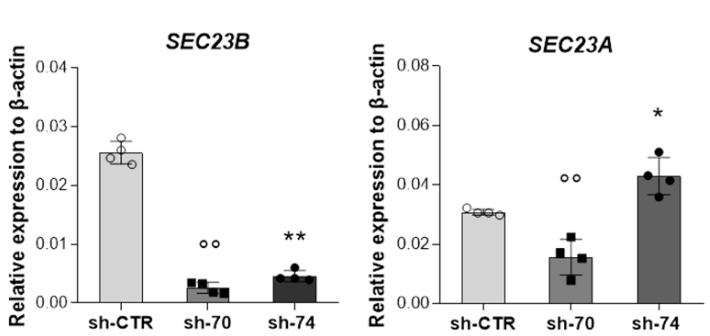

B

C

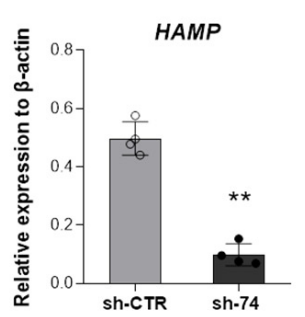

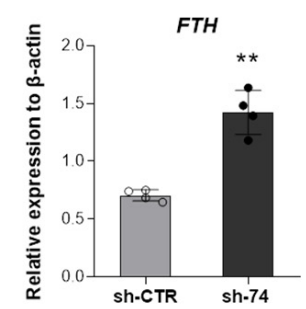

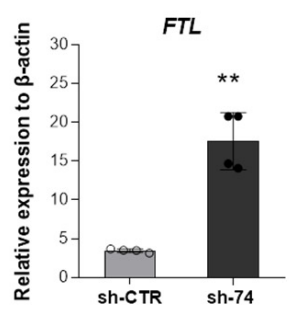

D

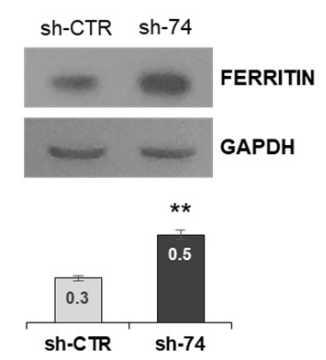

Figure 2. Characterization of $\mathbf{H u H 7}$ silenced for SEC23B. (A) SEC23B and SEC23A gene expression in HuH7 clones silenced for SEC23B, sh-SEC23B-70 (sh-70), and sh-SEC23B-74 (sh-74) compared to control cells (sh-CTR). Data are means \pm standard deviation of three independent experiments ( $p<0.05$, sh-CTR vs. sh-74; ${ }^{* *} p<0.01$, sh-CTR vs. sh-74; ${ }^{\circ} p<0.01$, sh-CTR vs. sh-70; Student's t-test). (B) Representatives immunoblot of SEC23B and SEC23A in HuH7 sh-70, sh-74, and sh-CTR cells (left panel) and densitometry quantification (right panel). Data are means \pm standard deviation of three independent experiments $\left(* * p<0.01\right.$, sh-CTR vs. sh-74; ${ }^{\circ} p<0.01$, sh-CTR vs. sh-70; Student's $t$-test). (C) HAMP, FTL, and FTH gene expression in HuH7 sh-74 compared to HuH7 sh-CTR cells. Data are means \pm standard deviation of three independent experiments $\left({ }^{* *} p<0.01\right.$; Student's t-test). (D) Representatives immunoblot of ferritin in HuH7 sh-74 compared to HuH7 shCTR cells and densitometry quantification. Data are means \pm standard deviation of three independent experiments ${ }^{* *} p<0.01$; Student's $t$-test).

The silencing experiment was carried out also in another human hepatic cell line, i.e., HepG2 cells. Of note, we observed comparable results using both shRNAs. The shSEC23B-74 clone showed higher efficiency and specificity for SEC23B silencing compared to the sh-SEC23B-70 also in HepG2 cells (Figure S1A,B). For this reason, we chose this sh-SEC23B-74 for further analysis.

In the HuH7 sh-SEC23B-74 clone, we found reduced expression of HAMP gene and increased expression of FTH and FTL genes compared to sh-CTR cells (Figure 2C,D). Protein expression analysis also showed an increase of ferritin expression in silenced cells compared to control ones (Figure 2D). Similarly, we observed reduced HAMP gene expression and increased expression of ferritin in HepG2 sh-SEC23B-74 cells compared to sh-CTR cells (Figure S1C,D).

2.3. SEC23B Loss-of-Function Alters BMP/SMADs Pathway and Fails to Activate the Signaling in Response to BMP6

To further characterize the alteration of iron status in SEC23B-silenced HuH7 cells, we evaluated the main components of the BMP/SMADs pathway, which is the main regulatory pathway of $H A M P$ gene expression [23] Firstly, we evaluated the phosphorylation levels of SMAD1/5/8 (pSMAD1/5/8, the receptor-activated effector of the pathway) and the protein expression of SMAD7 (inhibitor of the signaling) in our cellular system. We found strongly reduced levels of pSMAD1/5/8 and increased expression of SMAD7 in HuH7 sh-SEC23B-74 cells compared to control ones (Figure 3A). Similar results were obtained in HepG2 sh-SEC23B-74 cells compared to control ones (Figure S2A). 
A

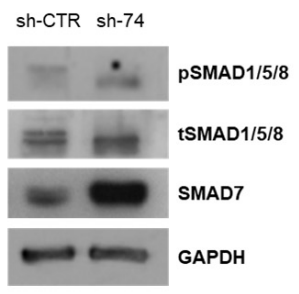

C
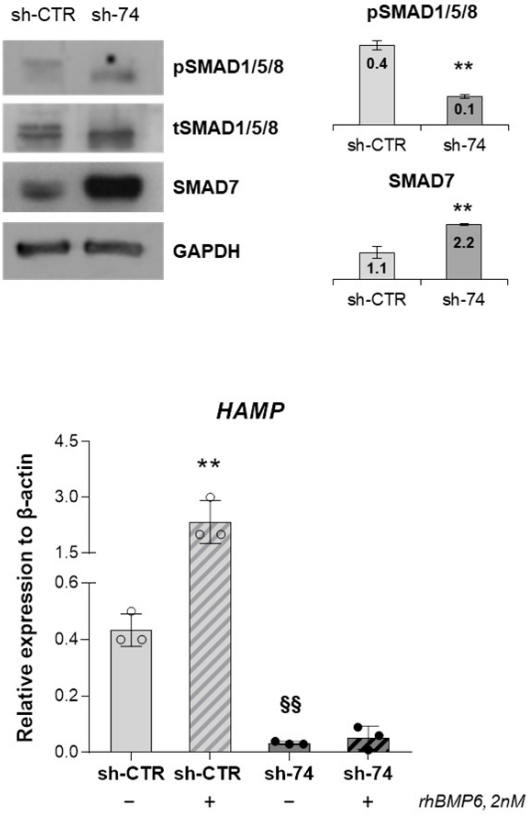

B
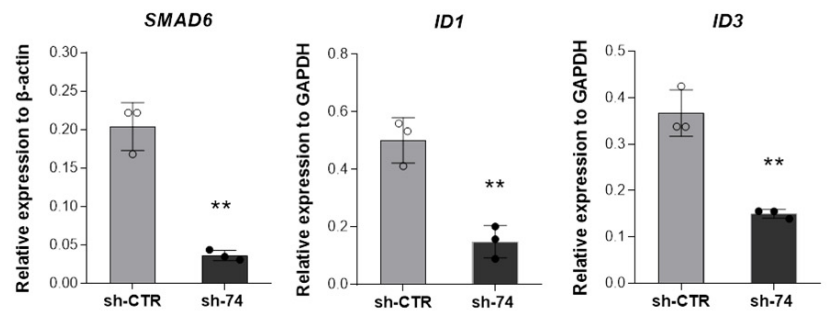

D

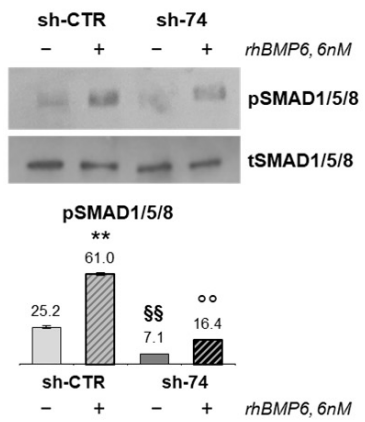

Figure 3. Evaluation of the activation of BMP/SMADs pathway in SEC23B-silenced HuH7. (A) Left panel. Representative immunoblots of pSMAD1/5/8, tSMAD1/5/8 and SMAD7 proteins in total cells lysate of $\mathrm{HuH7}$ sh-74 and sh-CTR cells. GAPDH is the loading control. Right panel. Quantification by densitometric analysis of three separate Western blots with similar results. Data are means \pm standard deviation (** $p<0.01$; Student's $t$-test). (B) SMAD6, ID1, and ID3 gene expression in HuH7 sh-74 and sh-CTR cells. Data are means \pm standard deviation of three independent experiments. (** $p<0.01$; Student's $t$-test). (C) HAMP gene expression in control HuH7 and sh74-SEC23B HuH7 cells treated or not with rhBMP6 $(2 \mathrm{nM})$. Data are means \pm standard deviation of three independent experiments. $\left({ }^{* *} p<0.01\right.$, sh-CTR + vehicle vs. sh-CTR + rhBMP6 (2 nM); ANOVA test and post-hoc correction by Tukey's multiple comparison tests; $\$ \S p<0.01$, sh-CTR vs. sh-74; Student's $t$-test). (D) Representative immunoblots of pSMAD1/5/8 and tSMAD1/5/8 proteins in total lysate of HuH7 sh-74 and sh-CTR cells treated (+) or not (-) with rhBMP6 (6nM). Densitometric analysis of three separate Western blots with similar results is shown $\left({ }^{* *} p<0.01\right.$, sh-CTR + vehicle vs. sh-CTR + rhBMP6 (6 nM); ${ }^{\circ \circ} p<0.01$, sh-CTR + vehicle vs. sh-CTR + $\operatorname{rhBMP6~(6nM);~} \S p<0.01$, sh-CTR vs. sh-74; Student's $t$-test).

The inhibition of BMP/SMADs pathway was also assessed by gene expression analysis of some target genes. Particularly, SMAD6, ID1, and ID3 gene expression resulted downregulated in $\mathrm{HuH7}$ sh-SEC23B-74 cells compared to control cells (Figure 3B).

Finally, we tested whether the loss of SEC23B affected the BMP/SMADs pathway activation. To this aim, we treated both sh-CTR and sh-SEC23B-74 clones with recombinant BMP6. Liver endothelial cells regulate HAMP transcription by producing BMP6, which activates the intracellular BMP/SMADs signaling [29]. In BMP6 treated cells, we evaluated both the HAMP gene expression and pSMAD1/5/8 levels. As expected, we observed a strong increase in HAMP expression and pSMAD1/5/8 levels in HuH7 sh-CTR cells treated with BMP6 compared to non-treated ones. Conversely, the BMP6 treatment did not increase HAMP gene expression in $\mathrm{HuH7}$ sh-SEC23B-74 cells treated with BMP6 compared to sh-SEC23B-74 not-treated cells (Figure 3C). Moreover, we observed only a slight increase of phosphorylation levels of SMAD1/5/8 in HuH7 sh-SEC23B-74 cells treated with BMP6 compared to sh-SEC23B-74 not-treated cells (Figure 3D). These data suggested that SEC23Bsilenced cells were not responsive to BMP6 stimulus. 


\subsection{Inhibition of N-Glycosylation Accounts for Reduced Activation of BMP/SMADs Pathway}

To understand the absence of activation of BMP/SMADs pathway after BMP6 stimulation in SEC23B-silenced cells, we further investigated the signaling pathway by assessing the protein expression of the main components of the multiprotein membrane complex (composed by TFR2, HFE, and HJV) that transduces the external BMP6 stimulus inside cells. We demonstrated a decreased protein expression of TFR2, HFE, and HJV in HuH7 sh-SEC23B-74 cells compared to control cells by Western blotting (WB) analysis (Figure 4A). Comparable results were obtained in HepG2 sh-SEC23B-74 cells compared to control ones (Figure S2B). Interestingly, a decreased protein expression of the negative regulator of the BMP/SMADs signaling, i.e., TMPRSS6, was also observed in both HuH7- and HepG2silenced cells (Figure 4A and Figure S2B).

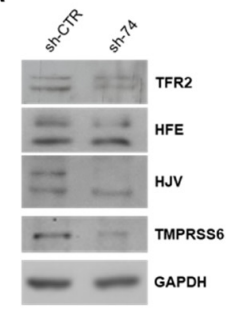

C

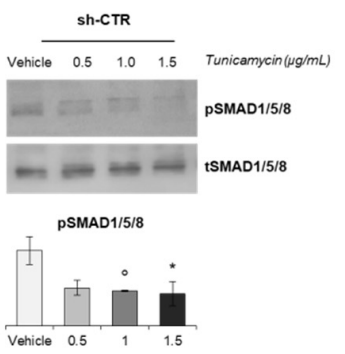

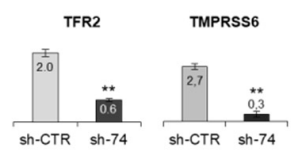
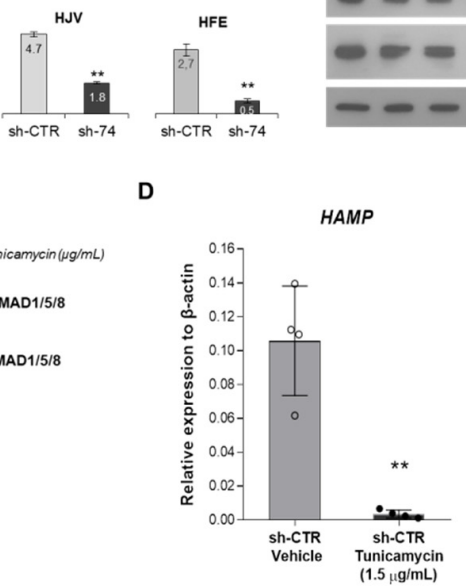

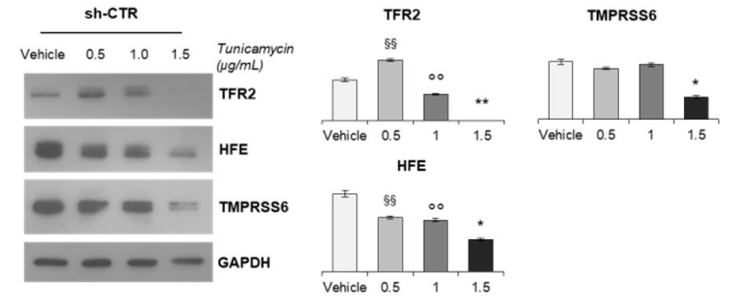

Figure 4. N-linked glycosylation is required for proper BMP/SMADs signaling. (A) Left panel. Representative immunoblots of TFR2, HFE, HJV, and TMPRSS6 proteins in total cells lysate of HuH7 sh-74 and sh-CTR cells. GAPDH is the loading control. Right panel. Quantification by densitometric analysis of three separate Western blots with similar results. Data are means \pm standard deviation. (** $p<0.01$; Student's $t$-test). (B) Left panel. Representative immunoblots of TFR2, HFE, and TMPRSS6 in HuH7 control cells treated with DMSO (vehicle) or increasing concentration of tunicamycin $(0.5,1.0,1.5 \mu \mathrm{g} / \mathrm{mL})$. GAPDH is the loading control. Right panel. Quantification by densitometric analysis of three separate Western blots with similar results. Data are means \pm standard deviation. (** $p<0.01,1.5 \mu \mathrm{g} / \mathrm{mL}$ tunicamycin-treated cells vs. vehicle, ${ }^{\circ \circ} p<0.01$ of $1.0 \mu \mathrm{g} / \mathrm{mL}$ tunicamycintreated cells vs. vehicle, $\S \S p<0.010 .5 \mathrm{ug} / \mathrm{mL}$ tunicamycin-treated cells vs. vehicle; ${ }^{*} p<0.05$, $1.5 \mu \mathrm{g} / \mathrm{mL}$ tunicamycin-treated cells vs. vehicle; ANOVA test and post-hoc correction by Tukey's multiple comparison tests). (C) Upper panel. Representative immunoblots of pSMAD1/5/8 and tSMAD1/5/8 proteins in HuH7 control cells treated with DMSO (vehicle) and increasing concentration of tunicamycin $(0.5,1.0,1.5 \mu \mathrm{g} / \mathrm{mL})$. Lower panel. Quantification by densitometric analysis of three separate Western blots with similar results. Data are means \pm standard deviation $\left({ }^{*} p<0.05\right.$, $1.5 \mu \mathrm{g} / \mathrm{mL}$ tunicamycin-treated cells vs. vehicle, ${ }^{\circ} p<0.05$ of $1.0 \mu \mathrm{g} / \mathrm{mL}$ tunicamycin-treated cells vs. vehicle. ANOVA test and post-hoc correction by Tukey's multiple comparison tests). (D) Quantification of HAMP gene expression in sh-CTR cells treated with DMSO and tunicamycin $(1.5 \mu \mathrm{g} / \mathrm{mL})$. Data are means \pm standard deviation of three independent experiments. ( ${ }^{* *} p<0.01$; Student's $t$-test).

Abnormalities in SEC23B affect different glycosylation pathways in CDA II. We hypothesized a role of impaired glycosylation of the multiprotein membrane complex proteins as causative of their altered expression. As proof of concept, we treated HuH7 control cells with increasing concentrations of tunicamycin $(0.5,1.0,1.5 \mu \mathrm{g} / \mathrm{mL})$, a drug that blocks $\mathrm{N}$ - 
linked glycosylation. Of note, N-linked glycosylation is necessary for the correct folding of the multiprotein membrane complex. We found a direct correlation between the increased concentration of tunicamycin and the progressive reduction of protein expression of TFR2, TMPRSS6, and HFE (Figure 4B). As consequence of the downregulation of this membrane complex, we observed a marked reduction of the phosphorylation levels of SMAD1/5/8 in the cells treated with tunicamycin (Figure $4 \mathrm{C}$ ). The final effect of this treatment was the downregulation of HAMP gene expression (Figure 4D).

\subsection{SEC23A Over-Expression Rescues the Impaired BMP/SMADs Signaling}

We performed a rescue experiment by overexpressing the SEC23B paralog, SEC23A, in $\mathrm{HuH7}$ SEC23B-silenced cells. Indeed, it was demonstrated that low SEC23B expression results in a compensatory increase in the paralog gene, SEC23A in CDA II patients [28]. To this aim, human SEC23A full-length ORF was transfected into HuH7 sh-SEC23B-74 cells for $48 \mathrm{~h}$. The over-expression of SEC23A was verified at both mRNA and protein level (Figure 5A). Interestingly, the overexpression of SEC23A rescued the downregulation of HAMP gene expression in SEC23B-silenced cells (Figure 5B). Additionally, we observed increased phosphorylation levels of SMAD1/5/8 (Figure 5C) with subsequent increased expression of SMAD6, ID1, and ID3 genes in SEC23B-silenced cells transiently transfected with SEC23A (Figure 5D).

A

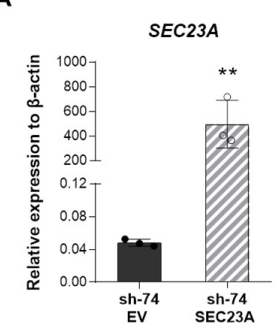

D

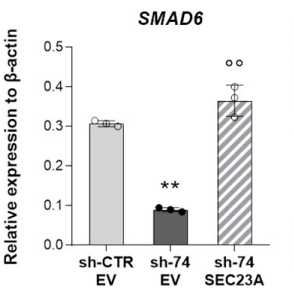

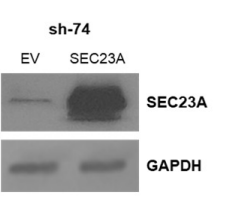

B

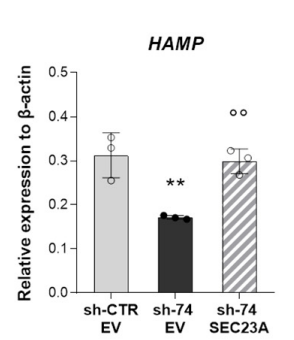

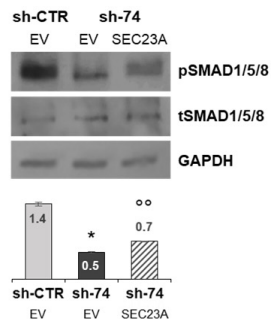
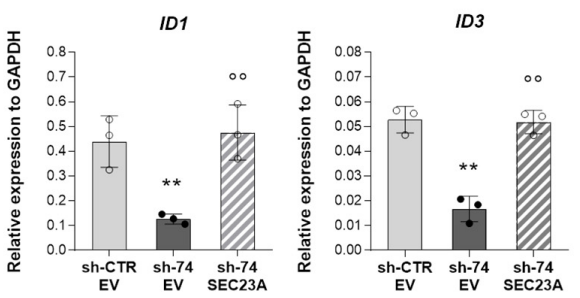

Figure 5. SEC23A overexpression in HuH7 SEC23B-silenced cells. (A) Left panel. SEC23A gene expression in sh-74 cells over-expressing empty vector (EV) and SEC23A coding sequence. Data are means \pm standard deviation of three independent experiments. $\left({ }^{*} p<0.01\right.$, sh-74 + EV vs. sh-74 + SEC23A; Student's $t$-test). Right panel. Representatives immunoblot of SEC23A protein in total cells lysate of sh-74 HuH7 cells over-expressing EV and SEC23A. (B) HAMP gene expression in sh-CTR HuH7 cells treated with EV, compared to both sh-74 + EV and sh-74 + SEC23A HuH7 cells. Data are means \pm standard deviation of three independent experiments. $(* * p>0.01$, shCTR + EV vs. sh-74 + EV, ${ }^{\circ \circ} p<0.01$, sh-74 + EV vs. sh-74 + SEC23A; ANOVA test and post-hoc correction by Tukey's multiple comparison tests). (C) Representatives immunoblot of pSMAD1/5/8 and $\mathrm{tSMAD1} / 5 / 8$ proteins in total cell lysate of sh-CTR HuH7 cells treated with EV, compared to both sh-74 + EV and sh-74 + SEC23A HuH7 cells. GAPDH is used as loading control ${ }^{*} p<0.05$, sh-CTR + EV vs. sh-74 + EV, ${ }^{\circ 0} p<0.01$, sh-74 + EV vs. sh-74 + SEC23A; ANOVA test and post-hoc correction by Tukey's multiple comparison tests). (D) SMAD6, ID1, and ID3 gene expression in sh-CTR HuH7 cells treated with EV, compared to both sh-74 + EV and sh-74 + SEC23A HuH7 cells. Data are means \pm standard deviation of three independent experiments ${ }^{* *} p>0.01$, sh-CTR $+\mathrm{EV}$ vs. sh-74 + EV, ${ }^{\circ \circ} p<0.01$, sh-74 + EV vs. sh-74 + SEC23A; ANOVA test and post-hoc correction by Tukey's multiple comparison tests). 


\section{Discussion}

Congenital dyserythropoietic anemia type II is the most frequent subtype among the CDAs, a heterogeneous group of rare hereditary anemias hallmarked by ineffective erythropoiesis and iron overload. Most CDA II patients are mildly affected. However, despite the monogenic origin of the disease, a high clinical heterogeneity among affected subjects was observed. This high clinical heterogeneity can be partially explained with co-inheritance of additional genetic variants in modifier genes $[3,10,11,15]$. Indeed, approximately $30 \%$ of CDA II patients exhibit a tendency to iron overload (ferritin $>300 \mathrm{ng} / \mathrm{mL}$ ), while $17 \%$ of them show marked hemosiderosis (ferritin $>600 \mathrm{ng} / \mathrm{mL}$ ) even regardless of the regimen of transfusion dependence [15].

The pathogenetic mechanism of iron overload was associated to expanding abnormal erythropoiesis that stimulates iron absorption in CDA II $[15,21,24,30]$. It is now clear that stimulated erythrocyte precursors produce one or more hepcidin-suppressive factors [31,32]. Currently, the main known erythroid regulator involved in hepcidin regulation is ERFE [16-19,21,33,34]. Erythroferrone mediates the suppression of HAMP expression by acting as ligand trap for BMPs, blocking the activation of the BMP/SMADs pathway $[18,23,33,35]$. In our previous studies, we demonstrated the overexpression of ERFE as an important determinant of altered iron balance in CDA II patients $[18,19,36]$. Nevertheless, we did not observe a clear correlation between ERFE levels and CDA II iron balance, thus suggesting that ERFE cannot be the only erythroid regulator of hepcidin suppression in these patients [19]. We herein described a case series of 28 CDA II patients showing iron overload with high transferrin saturation and very low levels of hepcidin. Of note, $36 \%(10 / 28)$ of them showed mild degree of anemia and slightly increased levels of ERFE despite the high EPO levels. Accordingly, we did not observe any correlation between ERFE and EPO levels in this case series, suggesting that additional elements take part in hepatic iron overload in CDA II.

Since $S E C 23 B$ is a ubiquitously expressed gene, we hypothesized a direct role of its loss-of-function in hepcidin regulation at hepatic level. We firstly established two hepatic cell line, HuH7 and HepG2, stably silenced for SEC23B. We demonstrated that silencing of $S E C 23 B$ leads to impaired activation of BMP/SMADs signaling pathway, which is responsible of hepcidin transcription [20-23,37,38]. Indeed, in silenced cells, we observed a reduction of the phosphorylation levels of SMAD1/5/8 that leads to the downregulation of the BMP/SMADs target genes, i.e., HAMP, SMAD6, ID1, and ID3. Moreover, we also observed an increased expression of ferritin, which correlates with the high levels of ferritinemia encountered in the patients with CDA II.

The suppression of hepcidin by ERFE is mediated by interference with paracrine BMP/SMADs signaling that regulates hepcidin transcription in hepatocytes [17]. To mimic this physiological mechanism, we tested the efficiency of HuH7 sh-SEC23B-74 cells in activating the pathway after BMP6 stimulation. We observed that HuH7 SEC23B-silenced cells did not activate the signaling after BMP6 stimulus compared to control cells. These data suggested that SEC23B-silenced cells failed to transduce external BMP6 stimulus inside the cytoplasm. The link between the extracellular BMP6-dependent signal and the activation of pSMAD1/5/8 requires the assembly of a multiprotein complex that regulates the pathway [20]. The hereditary hemochromatosis-associated membrane proteins HFE, TFR2, and HJV are required for adequate hepatic expression of the iron hormone hepcidin [39-41]. Moreover, TMPRSS6 acts as negative regulator of the pathway by the cleavage of HJV [42,43]. In our SEC23B-silenced cells, HFE, TFR2, TMPRSS6, and HJV were strongly down-regulated compared to control cells. These proteins have in common the complex post-translational modification that requires $\mathrm{N}$-glycosylation for the correct localization (HFE), activation (TMPRSS6), and stabilization (TFR2) in the plasma membrane [44-46]. As proof of concept, we treated HuH7 cells with tunicamycin, an N-linked glycosylation inhibitor [47]. Treatment with increasing concentrations of tunicamycin demonstrated that the altered glycosylation led to a reduced expression of TFR2, HFE, and TMPRSS6 proteins. Furthermore, also SMAD1/5/8 phosphorylation was strongly 
reduced after tunicamycin treatment, leading to suppressed HAMP gene expression. These data suggest that altered glycosylation is directly involved in regulation of hepatic iron metabolism (Figure 6). Our data are in agreement with the biochemical hallmark of CDA II, the hypoglycosylation of band 3 on red blood cell surface, which suggests defective glycosylation as pathogenetic mechanism of this disorder. Additionally, this defective glycosylation is not confined to erythrocyte compartment since altered glycosylation was also observed for TFR1 and TFR2 proteins [46].

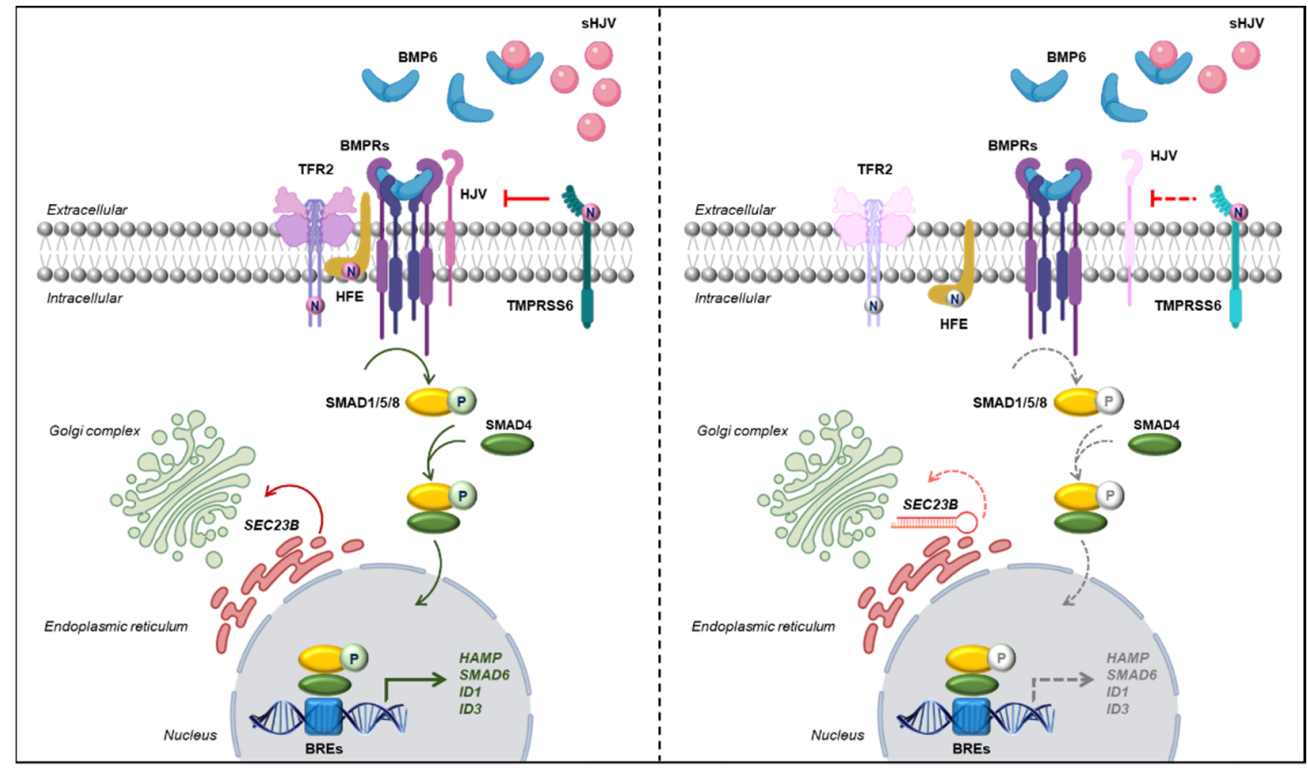

Figure 6. Schematic models of the mechanism of iron overload in SEC23B loss-of-function hepatic cells. Left panel. At physiological conditions, SEC23B mediates the anterograde trafficking of correctly folded proteins and post-translational modification. Correctly processed proteins (TFR2, HJV, HFE) associated in the membrane complex that mediates activation of BMP/SMADs pathway. The activation of the complex results in the phosphorylation of SMAD1/5/8 that in turn mediates the activation of the transcription of the BMP target genes, HAMP, SMAD6, ID1, and ID3. Right panel. SEC23B loss-of-function determines the decreased glycosylation of membrane proteins TFR2, HFE, and HJV (light colored), which accounts for the reduced expression and stabilization of the membrane complex. Therefore, BMP6 failed to activate the pathway, and this finally causes the suppression of HAMP gene transcription.

This study also highlighted for the first time the functional overlap between the two SEC23 paralogs in human hepatic cells. Indeed, we demonstrated that overexpression of SEC23A in SEC23B-silenced cells completely rescued the observed phenotype by reactivating BMP/SMADs signaling pathway and HAMP transcription. This is in agreement with a recent study on an erythroid SEC23B-deficient cellular model (HUDEP-2), whose CDA II phenotype was rescued by increased expression of SEC23A [48]. These results are highly relevant to suggest novel therapeutic approach for CDA II. Indeed, in-vitro gene therapy with lentiviral transduction of p60-BBF2H7, a transactivator of Sec23a, has been shown to compensate for mutated $S E C 23 B$ in primary human erythroblasts isolated from CDA II patients [49].

Our data strongly support the concept that increasing the expression of the SEC23A gene may prove a novel therapeutic strategy for CDA II not only for the treatment of anemia but also of the iron overload that remains the most harmful complication of this condition. 


\section{Materials and Methods}

\subsection{Patients}

Twenty-eight patients with CDA II were enrolled in the study, all showing iron overload defined as TSAT > 45\%. CDA II diagnosis was based on clinical findings and biochemical and molecular analyses, as previously reported [2-4,24,25]. Patients were furtherly stratified into two age- and gender-matched subgroups based on Hb levels: (i) mildly affected subjects $(\mathrm{Hb} \geq 10.0 \mathrm{~g} / \mathrm{dL} ; n=10)$ and (ii) moderately/severely affected cases $(\mathrm{Hb}$ $<10.0 \mathrm{~g} / \mathrm{dL} ; n=18$ ). Overall clinical features of enrolled patients are shown in Table 1. The Ethical Committee of University of Naples approved the collection of the patient data from the Medical Genetics Ambulatory in Naples (DAIMedLab, 'Federico II' University, protocol n.252/18 October 2018). Plasma samples from the patients were obtained after signed informed consent and according to the Declaration of Helsinki.

\subsection{Hepcidin, ERFE, and Erythropoietin Levels in Plasma Samples}

Plasma samples were collected from peripheral blood of patients and healthy controls after signed informed consent, according to Declaration of Helsinki. Plasma levels of Hepcidin (Intrinsic HEPCIDIN IDx, Intrinsic Lifesciences), human ERFE (hERFE) (Intrinsic Erythroferrone IE; Intrinsic Lifesciences, La Jolla, California, USA), erythropoietin (EPO) (Quantikine IVD ELISA Human Erythropoietin), and sTfR (Quantikine IVD ELISA Human sTfR, R\&D System Minneapolis, Minnesota, USA) were quantified using ELISA kits. The concentration of each parameter in each sample was determined through the fitting of a four-parameter logistic curve, according to the manufacturer protocols.

\subsection{Production of Lentiviral Particles and Infection of the HuH7 and HepG2 Cell Line}

Knock-down of SEC23B expression was obtained through infection of lentiviral particles that targeted human SEC23B of HuH7 and HepG2 hepatic carcinoma cell lines, as previously described [50]. After $48 \mathrm{~h}$, Puromycin $(2 \mu \mathrm{g} / \mathrm{mL})$ was added as a selection marker. Single, resistant colonies were transferred in a 96-well and then expanded. The infection efficiency was assessed by testing gene and protein expression of SEC23B and SEC23A compared to control HUH7/HepG2 cells.

\subsection{Culture of Cell Lines and Drugs Treatments}

HuH7 (differentiated human hepatoma) cell line was obtained from Japan Health Science Research Resources Bank (Rinku Town, Osaka, Japan) and previously used [18,36]. The wild-type (control) HuH7 cells and SEC23B-silenced HuH7 stable clones were maintained in Dulbecco's modified Eagle's medium (Sigma Aldrich, Milan, Italy), supplemented with 10\% (v/v) fetal bovine serum (Life Technologies; CA, USA), $100 \mathrm{U} / \mathrm{mL}$ penicillin (Life Technologies, Carlsbad, California, USA), and $100 \mathrm{mg} / \mathrm{mL}$ streptomycin (Life Technologies) at $37^{\circ} \mathrm{C}$ in humidified air/CO2 (19:1) atmosphere. HepG2 (hepatocyte carcinoma) cells were obtained from American Type Culture Collection (ATCC, Manassas, VA, United States) and maintained following the manufacturer's instruction. [18,51]. The wild-type (control) HepG2 cells and SEC23B-silenced HepG2 stable clones were cultured in RPMI 1640 (Sigma Aldrich, Milan, Italy) supplemented with 10\% (v/v) fetal bovine serum (Life Technologies), $100 \mathrm{U} / \mathrm{mL}$ penicillin (Life Technologies), and $100 \mathrm{mg} / \mathrm{mL}$ streptomycin (Life Technologies), at $37^{\circ} \mathrm{C}$ in humidified air $/ \mathrm{CO} 2$ (19:1) atmosphere.

Recombinant human BMP6 protein (507-BP-020; R\&D Systems, Minneapolis, MN, USA) was used at $2 \mathrm{nM}(90 \mathrm{~min})$ and $6 \mathrm{nM}$ (30 $\mathrm{min})$ [33]. Tunicamycin (T7765, Sigma Aldrich) was added at increasing concentration $(0.5,1.0,1.5 \mu \mathrm{g} / \mathrm{mL})$ [52]; DMSO was used as a vehicle. Precision LentiORF Human SEC23A (3 $\mu$ g) (Horizon) was transiently transfected into SEC23B-silenced HuH7 using FuGENE HD transfection Reagent (Promega, Cells were harvested at 0,24 , and $48 \mathrm{~h}$. 


\subsection{Gene Expression Analysis}

Total RNA was extracted from cells using TRIzol reagent (Life Technologies, Waltham, MA, USA). Synthesis of cDNA from total RNA $(1 \mu \mathrm{g})$ was performed using cDNA synthesis kits (Life Technologies). Quantitative real-time PCR (qRT-PCR) analysis was carried out using Power SYBR Green PCR Master Mix (Life Technologies) to evaluate the expression of SEC23B, SEC23A, FTH, FTL, HAMP, and SMAD6 genes. $\beta$-Actin and GAPDH genes were used as the internal controls. The primers were designed with the Primer Express 2.1 software (Applied Biosystems, Waltham, Massachusetts, Stati Unit). Primer sequences are available upon request (roberta.russo@unina.it). Expression analysis of ID1 and ID3 genes was performed using a standard TaqMan PCR kit protocol. (ID1: Hs03676575_s1; ID3: Hs00171409_m1; GAPDH Hs99999905_m1; Applied Biosystem) The samples were amplified by 7900 HT Sequence Detection System (Applied Biosystems) using standard cycling conditions. Relative gene expression was calculated either by the $2^{-\Delta \mathrm{Ct}}$ method, with the fold change determined using the ratio between the gene expression and the internal control, or by the mean fold change $2^{\text {-(average } \Delta \Delta \mathrm{Ct})}$, determined using the mean difference in $\Delta \mathrm{Ct}$ between the gene and the internal control.

\subsection{Protein Expression Analysis}

Proteins were extracted from the cells using RIPA lysis buffer in the presence of a protease inhibitor cocktail (Roche, Rotkreuz, Switzerland). Protein extracts have been quantified using Bradford dye-binding method (BioRad, Milan, Italy). Total protein extracts were analyzed by SDS-PAGE, transferred to polyvinylidene difluoride membranes (BioRad, Milan, Italy), and then incubated with the required combinations of the following antibodies: rabbit anti-SEC23B (1:1000; SAB2102104; Sigma Aldrich); SEC23A; Rabbit anti-Ferritin (1:1000; Abcam, ab75973); polyclonal rabbit Anti-Transferrin Receptor 2 (1:1000, Abcam, ab80194); monoclonal rabbit anti-HFE (1:1000. Abcam, ab133639); monoclonal rabbit antiTMPRSS6 (1:1000, Abcam, ab56180); monoclonal rabbit anti-pSMAD 1/5/8 (1:1000, Cell Signalling, 13820); polyclonal rabbit anti-tSMAD 1/5/8/9 (1:1000, abcam, ab13723); rabbit anti-GAPDH (1:1000; 2118, Cell Signaling Technology Danvers, Massachusetts, USA); and Rabbit anti-HJV, which was kindly gifted by Laura Silvestri. Semi-quantitative analysis of protein expression was performed as previously described [36]. The bands were quantified using the Quantity One software (BioRad, Milan, Italy) to obtain integrated optical densities, which were then normalized to GAPDH.

\subsection{Statistical Analysis}

Statistical significances of the differences in protein and gene expression were determined using Student's $t$-tests. Statistical significances of multiple comparisons were calculated using ANOVA, and post-hoc correction was performed using Tukey's multiple comparison tests. A two-sided $p<0.05$ was considered statistically significant.

\section{Conclusions}

We herein demonstrated, for the first time, a direct role of SEC23B loss-of-function variants as contributing cause of CDA II-related iron overload at hepatic level. Our data might explain CDA II cases showing marked iron overload despite mild or slight degree of anemia where the role of ERFE seems to be secondary. Moreover, understanding the molecular mechanism that underlies SEC23B loss-of-function at hepatic level shed light on new therapeutic strategies of iron overload in CDA II.

Supplementary Materials: The following supporting information can be downloaded at: https:// www.mdpi.com/article/10.3390/ijms23031304/s1.

Author Contributions: Conceptualization, I.A., R.R. and B.E.R.; methodology, F.D.G. and S.D.M.; validation, V.D., F.D.G. and S.D.M.; formal analysis, B.E.R. and R.M.; writing-original draft preparation, B.E.R.; writing-review and editing, R.R. and I.A.; supervision, A.I.; funding acquisition, I.A. and R.R. All authors have read and agreed to the published version of the manuscript. 
Funding: This research was funded by EHA Junior Research Grant to Immacolata Andolfo (3978026), and by Bando Star Linea 1-Junior Principal Investigator Grants-COINOR, Università degli Studi di Napoli ‘Federico II' to Roberta Russo.

Institutional Review Board Statement: The study was conducted according to the guidelines of the Declaration of Helsinki, and the local University Ethical Committee approved the collection of the patient data (DAIMedLab, 'Federico II' University of Naples; NO. 252/18).

Informed Consent Statement: DNA samples were obtained from the patients after they had signed their informed consent and according to the Declaration of Helsinki.

Data Availability Statement: Data sharing not applicable.

Acknowledgments: The authors thank Laura Silvestri for kindly providing the HJV antibody.

Conflicts of Interest: The authors declare no conflict of interest.

\section{References}

1. Gambale, A.; Iolascon, A.; Andolfo, I.; Russo, R. Diagnosis and management of congenital dyserythropoietic anemias. Expert Rev. Hematol. 2016, 9, 283-296. [CrossRef] [PubMed]

2. Heimpel, H. Congenital dyserythropoietic anemias: Epidemiology, clinical significance, and progress in understanding their pathogenesis. Ann. Hematol. 2004, 83, 613-621. [CrossRef] [PubMed]

3. Iolascon, A.; Esposito, M.R.; Russo, R. Clinical aspects and pathogenesis of congenital dyserythropoietic anemias: From morphology to molecular approach. Haematologica 2012, 97, 1786-1794. [CrossRef] [PubMed]

4. Heimpel, H.; Kellermann, K.; Neuschwander, N.; Hogel, J.; Schwarz, K. The morphological diagnosis of congenital dyserythropoietic anemia: Results of a quantitative analysis of peripheral blood and bone marrow cells. Haematologica 2010, 95, 1034-1036. [CrossRef] [PubMed]

5. De Franceschi, L.; Turrini, F.; del Giudice, E.M.; Perrotta, S.; Olivieri, O.; Corrocher, R.; Mannu, F.; Iolascon, A. Decreased band 3 anion transport activity and band 3 clusterization in congenital dyserythropoietic anemia type II. Exp. Hematol. 1998, 26, 869-873. [PubMed]

6. Mawby, W.J.; Tanner, M.J.; Anstee, D.J.; Clamp, J.R. Incomplete glycosylation of erythrocyte membrane proteins in congenital dyserythropoietic anaemia type II (CDA II). Br. J. Haematol. 1983, 55, 357-368. [CrossRef]

7. Iolascon, A.; Delaunay, J. Close to unraveling the secrets of congenital dyserythropoietic anemia types I and II. Haematologica 2009, 94, 599-602. [CrossRef]

8. Zdebska, E.; Iolascon, A.; Spychalska, J.; Perrotta, S.; Lanzara, C.; Smolenska-Sym, G.; Koscielak, J. Abnormalities of erythrocyte glycoconjugates are identical in two families with congenital dyserythropoietic anemia type II with different chromosomal localizations of the disease gene. Haematologica 2007, 92, 427-428. [CrossRef]

9. Bianchi, P.; Fermo, E.; Vercellati, C.; Boschetti, C.; Barcellini, W.; Iurlo, A.; Marcello, A.P.; Righetti, P.G.; Zanella, A. Congenital dyserythropoietic anemia type II (CDA II) is caused by mutations in the SEC23B gene. Hum. Mutat. 2009, 30, $1292-1298$. [CrossRef]

10. Russo, R.; Esposito, M.R.; Iolascon, A. Inherited hematological disorders due to defects in coat protein (COP)II complex. Am. J. Hematol. 2013, 88, 135-140. [CrossRef]

11. Schwarz, K.; Iolascon, A.; Verissimo, F.; Trede, N.S.; Horsley, W.; Chen, W.; Paw, B.H.; Hopfner, K.P.; Holzmann, K.; Russo, R.; et al. Mutations affecting the secretory COPII coat component SEC23B cause congenital dyserythropoietic anemia type II. Nat. Genet. 2009, 41, 936-940. [CrossRef] [PubMed]

12. Fromme, J.C.; Orci, L.; Schekman, R. Coordination of COPII vesicle trafficking by Sec23. Trends Cell Biol. 2008, 18, 330-336. [CrossRef] [PubMed]

13. Unal, S.; Russo, R.; Gumruk, F.; Kuskonmaz, B.; Cetin, M.; Sayli, T.; Tavil, B.; Langella, C.; Iolascon, A.; Uckan Cetinkaya, D. Successful hematopoietic stem cell transplantation in a patient with congenital dyserythropoietic anemia type II. Pediatr. Transplant. 2014, 18, E130-E133. [CrossRef] [PubMed]

14. Uygun, V.; Russo, R.; Karasu, G.; Daloglu, H.; Iolascon, A.; Yesilipek, A. Hematopoietic Stem Cell Transplantation in Congenital Dyserythropetic Anemia Type II: A Case Report and Review of the Literature. J. Pediatr. Hematol. Oncol. 2019, 42, e507-e510. [CrossRef] [PubMed]

15. Russo, R.; Gambale, A.; Langella, C.; Andolfo, I.; Unal, S.; Iolascon, A. Retrospective cohort study of 205 cases with congenital dyserythropoietic anemia type II: Definition of clinical and molecular spectrum and identification of new diagnostic scores. Am. J. Hematol. 2014, 89, E169-E175. [CrossRef] [PubMed]

16. Kautz, L.; Jung, G.; Nemeth, E.; Ganz, T. Erythroferrone contributes to recovery from anemia of inflammation. Blood 2014, 124, 2569-2574. [CrossRef] [PubMed]

17. Ganz, T. Erythropoietic regulators of iron metabolism. Free Radic. Biol. Med. 2019, 133, 69-74. [CrossRef] 
18. Andolfo, I.; Rosato, B.E.; Marra, R.; De Rosa, G.; Manna, F.; Gambale, A.; Iolascon, A.; Russo, R. The BMP-SMAD pathway mediates the impaired hepatic iron metabolism associated with the ERFE-A260S variant. Am. J. Hematol. 2019, 94, 1227-1235. [CrossRef]

19. Russo, R.; Andolfo, I.; Manna, F.; De Rosa, G.; De Falco, L.; Gambale, A.; Bruno, M.; Matte, A.; Ricchi, P.; Girelli, D.; et al. Increased levels of ERFE-encoding FAM132B in patients with congenital dyserythropoietic anemia type II. Blood 2016, 128, 1899-1902. [CrossRef]

20. D'Alessio, F.; Hentze, M.W.; Muckenthaler, M.U. The hemochromatosis proteins HFE, TfR2, and HJV form a membrane-associated protein complex for hepcidin regulation. J. Hepatol. 2012, 57, 1052-1060. [CrossRef]

21. Muckenthaler, M.U.; Rivella, S.; Hentze, M.W.; Galy, B. A Red Carpet for Iron Metabolism. Cell 2017, 168, 344-361. [CrossRef] [PubMed]

22. Silvestri, L. The Iron Tale: If It Does Not Kill You, It Makes You Stronger (and Hepcidin Helps). Hemasphere 2018, 2, e27. [CrossRef]

23. Silvestri, L.; Nai, A.; Dulja, A.; Pagani, A. Hepcidin and the BMP-SMAD pathway: An unexpected liaison. Vitam. Horm. 2019, 110, 71-99. [CrossRef] [PubMed]

24. Iolascon, A.; Andolfo, I.; Russo, R. Congenital dyserythropoietic anemias. Blood 2020, 136, 1274-1283. [CrossRef] [PubMed]

25. Andolfo, I.; Martone, S.; Rosato, B.E.; Marra, R.; Gambale, A.; Forni, G.L.; Pinto, V.; Goransson, M.; Papadopoulou, V.; Gavillet, M.; et al. Complex Modes of Inheritance in Hereditary Red Blood Cell Disorders: A Case Series Study of 155 Patients. Genes 2021, 12, 958. [CrossRef]

26. Andolfo, I.; Russo, R.; Rosato, B.E.; Manna, F.; Gambale, A.; Brugnara, C.; Iolascon, A. Genotype-phenotype correlation and risk stratification in a cohort of 123 hereditary stomatocytosis patients. Am. J. Hematol. 2018, 93, 1509-1517. [CrossRef]

27. Iolascon, A.; Russo, R.; Esposito, M.R.; Asci, R.; Piscopo, C.; Perrotta, S.; Feneant-Thibault, M.; Garcon, L.; Delaunay, J. Molecular analysis of 42 patients with congenital dyserythropoietic anemia type II: New mutations in the SEC23B gene and a search for a genotype-phenotype relationship. Haematologica 2010, 95, 708-715. [CrossRef]

28. Russo, R.; Langella, C.; Esposito, M.R.; Gambale, A.; Vitiello, F.; Vallefuoco, F.; Ek, T.; Yang, E.; Iolascon, A. Hypomorphic mutations of SEC23B gene account for mild phenotypes of congenital dyserythropoietic anemia type II. Blood Cells Mol. Dis. 2013, 51, 17-21. [CrossRef]

29. Wang, S.; Chen, C.; Yu, L.; Mueller, J.; Rausch, V.; Mueller, S. Bone morphogenetic protein 6-mediated crosstalk between endothelial cells and hepatocytes recapitulates the iron-sensing pathway in vitro. J. Biol. Chem. 2021, 297, 101378. [CrossRef]

30. Ganz, T.; Nemeth, E. Iron metabolism: Interactions with normal and disordered erythropoiesis. Cold Spring Harb. Perspect. Med. 2012, 2, a011668. [CrossRef]

31. Adamsky, K.; Weizer, O.; Amariglio, N.; Breda, L.; Harmelin, A.; Rivella, S.; Rachmilewitz, E.; Rechavi, G. Decreased hepcidin mRNA expression in thalassemic mice. Br. J. Haematol. 2004, 124, 123-124. [CrossRef] [PubMed]

32. Papanikolaou, G.; Tzilianos, M.; Christakis, J.I.; Bogdanos, D.; Tsimirika, K.; MacFarlane, J.; Goldberg, Y.P.; Sakellaropoulos, N.; Ganz, T.; Nemeth, E. Hepcidin in iron overload disorders. Blood 2005, 105, 4103-4105. [CrossRef] [PubMed]

33. Arezes, J.; Foy, N.; McHugh, K.; Sawant, A.; Quinkert, D.; Terraube, V.; Brinth, A.; Tam, M.; LaVallie, E.R.; Taylor, S.; et al. Erythroferrone inhibits the induction of hepcidin by BMP6. Blood 2018, 132, 1473-1477. [CrossRef] [PubMed]

34. Coffey, R.; Ganz, T. Erythroferrone: An Erythroid Regulator of Hepcidin and Iron Metabolism. Hemasphere 2018, 2, e35. [CrossRef] [PubMed]

35. Wang, C.Y.; Core, A.B.; Canali, S.; Zumbrennen-Bullough, K.B.; Ozer, S.; Umans, L.; Zwijsen, A.; Babitt, J.L. Smad1/5 is required for erythropoietin-mediated suppression of hepcidin in mice. Blood 2017, 130, 73-83. [CrossRef] [PubMed]

36. Andolfo, I.; Rosato, B.E.; Manna, F.; De Rosa, G.; Marra, R.; Gambale, A.; Girelli, D.; Russo, R.; Iolascon, A. Gain-of-function mutations in PIEZO1 directly impair hepatic iron metabolism via the inhibition of the BMP/SMADs pathway. Am. J. Hematol. 2020, 95, 188-197. [CrossRef]

37. Casanovas, G.; Mleczko-Sanecka, K.; Altamura, S.; Hentze, M.W.; Muckenthaler, M.U. Bone morphogenetic protein (BMP)responsive elements located in the proximal and distal hepcidin promoter are critical for its response to HJV/BMP/SMAD. J. Mol. Med. 2009, 87, 471-480. [CrossRef]

38. Verga Falzacappa, M.V.; Casanovas, G.; Hentze, M.W.; Muckenthaler, M.U. A bone morphogenetic protein (BMP)-responsive element in the hepcidin promoter controls HFE2-mediated hepatic hepcidin expression and its response to IL-6 in cultured cells. J. Mol. Med. 2008, 86, 531-540. [CrossRef]

39. Gao, J.; Chen, J.; Kramer, M.; Tsukamoto, H.; Zhang, A.S.; Enns, C.A. Interaction of the hereditary hemochromatosis protein HFE with transferrin receptor 2 is required for transferrin-induced hepcidin expression. Cell Metab. 2009, 9, 217-227. [CrossRef]

40. Schmidt, P.J.; Andrews, N.C.; Fleming, M.D. Hepcidin induction by transgenic overexpression of Hfe does not require the Hfe cytoplasmic tail, but does require hemojuvelin. Blood 2010, 116, 5679-5687. [CrossRef]

41. Wallace, D.F.; Summerville, L.; Crampton, E.M.; Frazer, D.M.; Anderson, G.J.; Subramaniam, V.N. Combined deletion of Hfe and transferrin receptor 2 in mice leads to marked dysregulation of hepcidin and iron overload. Hepatology 2009, 50, 1992-2000. [CrossRef] [PubMed]

42. Silvestri, L.; Guillem, F.; Pagani, A.; Nai, A.; Oudin, C.; Silva, M.; Toutain, F.; Kannengiesser, C.; Beaumont, C.; Camaschella, C.; et al. Molecular mechanisms of the defective hepcidin inhibition in TMPRSS6 mutations associated with iron-refractory iron deficiency anemia. Blood 2009, 113, 5605-5608. [CrossRef] [PubMed] 
43. Silvestri, L.; Pagani, A.; Nai, A.; De Domenico, I.; Kaplan, J.; Camaschella, C. The serine protease matriptase-2 (TMPRSS6) inhibits hepcidin activation by cleaving membrane hemojuvelin. Cell Metab. 2008, 8, 502-511. [CrossRef] [PubMed]

44. Bhatt, L.; Murphy, C.; O’Driscoll, L.S.; Carmo-Fonseca, M.; McCaffrey, M.W.; Fleming, J.V. N-glycosylation is important for the correct intracellular localization of HFE and its ability to decrease cell surface transferrin binding. FEBS J. 2010, 277, 3219-3234. [CrossRef]

45. Jiang, J.; Yang, J.; Feng, P.; Zuo, B.; Dong, N.; Wu, Q.; He, Y. N-glycosylation is required for matriptase-2 autoactivation and ectodomain shedding. J. Biol. Chem. 2014, 289, 19500-19507. [CrossRef] [PubMed]

46. Zhao, N.; Enns, C.A. N-linked glycosylation is required for transferrin-induced stabilization of transferrin receptor 2, but not for transferrin binding or trafficking to the cell surface. Biochemistry 2013, 52, 3310-3319. [CrossRef] [PubMed]

47. Salzberger, W.; Garcia-Beltran, W.F.; Dugan, H.; Gubbala, S.; Simoneau, C.; Gressens, S.B.; Jost, S.; Altfeld, M. Influence of Glycosylation Inhibition on the Binding of KIR3DL1 to HLA-B*57:01. PLoS ONE 2015, 10, e145324. [CrossRef] [PubMed]

48. King, R.; Lin, Z.; Balbin-Cuesta, G.; Myers, G.; Friedman, A.; Zhu, G.; McGee, B.; Saunders, T.L.; Kurita, R.; Nakamura, Y.; et al. SEC23A rescues SEC23B-deficient congenital dyserythropoietic anemia type II. Sci. Adv. 2021, 7, eabj5293. [CrossRef]

49. Pellegrin, S.; Haydn-Smith, K.L.; Hampton-O’Neil, L.A.; Hawley, B.R.; Heesom, K.J.; Fermo, E.; Bianchi, P.; Toye, A.M. Transduction with BBF2H7/CREB3L2 upregulates SEC23A protein in erythroblasts and partially corrects the hypo-glycosylation phenotype associated with CDA II. Br. J. Haematol. 2019, 184, 876-881. [CrossRef]

50. De Rosa, G.; Andolfo, I.; Marra, R.; Manna, F.; Rosato, B.E.; Iolascon, A.; Russo, R. RAP-011 Rescues the Disease Phenotype in a Cellular Model of Congenital Dyserythropoietic Anemia Type II by Inhibiting the SMAD2-3 Pathway. Int. J. Mol. Sci. $2020,21$. [CrossRef]

51. Russo, R.; Marra, R.; Andolfo, I.; De Rosa, G.; Rosato, B.E.; Manna, F.; Gambale, A.; Raia, M.; Unal, S.; Barella, S.; et al. Characterization of Two Cases of Congenital Dyserythropoietic Anemia Type I Shed Light on the Uncharacterized C15orf41 Protein. Front Physiol 2019, 10, 621. [CrossRef] [PubMed]

52. Lunde, N.N.; Haugen, M.H.; Bodin Larsen, K.B.; Damgaard, I.; Pettersen, S.J.; Kasem, R.; Rut, W.; Drag, M.; Poreba, M.; Johansen, H.T.; et al. Glycosylation is important for legumain localization and processing to active forms but not for cystatin E/M inhibitory functions. Biochimie 2017, 139, 27-37. [CrossRef] [PubMed] 